\title{
Zebrafish sexual behavior: role of sex steroid hormones and prostaglandins
}

\author{
Ajay Pradhan and Per-Erik Olsson*
}

\begin{abstract}
Background: Mating behavior differ between sexes and involves gonadal hormones and possibly sexually dimorphic gene expression in the brain. Sex steroids and prostaglandin $E_{2}\left(P G E_{2}\right)$ have been shown to regulate mammalian sexual behavior. The present study was aimed at determining whether exposure to sex steroids and prostaglandins could alter zebrafish sexual mating behavior.

Methods: Mating behavior and successful spawning was recorded following exposure to 17 $\beta$-estradiol (E2), 11-ketotestosterone (11-KT), prostaglandin $\mathrm{D}_{2}\left(\mathrm{PGD}_{2}\right)$ and $P G E_{2}$ via the water. qRT-PCR was used to analyze transcript levels in the forebrain, midbrain, and hindbrain of male and female zebrafish and compared to animals exposed to E2 via the water.

Results: Exposure of zebrafish to sex hormones resulted in alterations in behavior and spawning when male fish were exposed to $\mathrm{E} 2$ and female fish were exposed to 11-KT. Exposure to $\mathrm{PGD}_{2}$, and $\mathrm{PGE}_{2}$ did not alter mating behavior or spawning success. Determination of gene expression patterns of selected genes from three brain regions using qRT-PCR analysis demonstrated that the three brain regions differed in gene expression pattern and that there were differences between the sexes. In addition, E2 exposure also resulted in altered gene transcription profiles of several genes.

Conclusions: Exposure to sex hormones, but not prostaglandins altered mating behavior in zebrafish. The expression patterns of the studied genes indicate that there are large regional and gender-based differences in gene expression and that E2 treatment alter the gene expression pattern in all regions of the brain.
\end{abstract}

Keywords: Brain transcriptomic, Forebrain, Midbrain, Hindbrain, Brain dimorphism, sexual behavior

\section{Background}

Males and females exhibit characteristic biological differences that include phenotypical and physiological traits. Apart from gonadal differences, brain sexual dimorphisms have been demonstrated in mammals [1, 2]. Male and female brain differences affect biochemical processes, disease susceptibility, as well as behavior [1,2]. The sex differences in behavior include courtship, mating, territorial marking, aggression, and parental care [2, $3]$. The gonadal steroid hormones play a critical role in regulating sexual behavior [4]. Interestingly, while both $17-\beta$ estradiol (E2) and testosterone (T) elicit male sexual

*Correspondence: per-erik.olsson@oru.se

Biology, The Life Science Center, School of Science and Technology, Örebro University, 70182 Örebro, Sweden behaviors in mammals, the molecular mechanisms are poorly understood [4].

Sex steroids have been indicated to both activate and organize brain functions. Already during fetal development sex steroids permanently organize neuronal pathways involved in reproductive behavior and later, at puberty, sex steroids released form the gonads activate these differentiated pathways [5]. Through androgen receptor (AR) activation, $\mathrm{T}$ can both activate and organize neuronal pathways. $\mathrm{T}$ can also be converted to dihydrotestosterone (DHT) and E2 by steroid biosynthesis enzymes in the brain. E2 carries out its function via the estrogen receptors (ER $\alpha$ and ER $\beta)$ [3, 4]. Studies with mutant mice lacking AR have indicated that while male mice develop testicles and male secondary sexual characters they exhibit diminished male typical behavior $[6,7]$. 
This has led to the formulation of a model where $\mathrm{T}$ and $\mathrm{E} 2$ have complementary roles in masculinization of the nervous system [6]. It has also been suggested that $\mathrm{T}$ aromatized to E2 amplifies male typical behavior while $\mathrm{T}$ acting through AR is needed to fully masculinize the brain [7].

$\mathrm{T}$ has been shown to masculinize the female brain in guinea pigs. Prenatal $\mathrm{T}$ treatment of female guinea pigs resulted in male typical behavior in adulthood, but the effect was not observed when $T$ treatment was performed on females either perinatally or in adulthood [5]. This suggests that the brain is organized towards masculinization or feminization during the embryonic or fetal periods and that the gonadal hormones activate neural tissues for expression of male or female typical behavior in adult animals [5]. However, the presence of critical periods for gonadal hormone action in organizing or programing the nervous system remains controversial as it has been shown that sexual dimorphism of the brain can be repatterned postnatally [8]. As E2 is known to masculinize the female brain [9], $\mathrm{T}$ was assumed to be converted to E2 by aromatase to regulate brain patterning. Subsequent studies have shown that E2 is involved in induction of cyclooxygenase 2, a key enzyme in prostaglandin $\mathrm{E}_{2}\left(\mathrm{PGE}_{2}\right)$ synthesis which has been suggested to regulate sexual behavior in mice [10].

Gonadal hormones and prostaglandins can modulate the central nervous systems of birds and mammals, altering sexual behavior. However, there is insufficient data on teleosts to link hormonal roles to neural circuit organization and sexual behavior. Teleosts demonstrate a remarkable ability to undergo sex reversal both by hormonal treatment and socially controlled cues [11]. Bluebanded gobies live in groups consisting of a dominant male with several females and show sex reversal in both directions. Removal of the male from the group triggers the largest female within the group to undergo gonadal, morphologi$\mathrm{cal}$, and behavioral changes to become a fertile male. During this transition, aromatase activity drops quicker in the brain than in the gonads [11]. Fadrazole, an inhibitor of aromatase, and 11-ketotestosterone (11-KT) treatment of the blackeye goby resulted in protogynous sex change [12]. Interestingly, the administration of nonaromatizable androgens, 11-KT and 11-ketosandrosterone, resulted in sex change while the aromatizable $17 \alpha$-methyltetosterone (MT) did not [12]. The gonadotropin releasing hormone (GnRH) neuron numbers in the preoptic area of the hypothalamus is higher in male bluehead wrasses and 11-KT treatment increases GnRH neurons and sex change in females [13]. When placed with a receptive female 11-KT treated female goldfish showed male typical behavior while $\mathrm{T}$ exposure resulted in low level of masculinization [14]. MT treatment has also been shown to induce male typical behavior in female goldfish [15] and in female three-spined stickleback [16]. On the other hand E2 treatment has been shown to result in male to female sex reversal in several different teleost species and affect male reproductive behavior [17-19]. This suggests that in teleost 11-KT induces male typical behavior in females and that E2 has feminizing properties.

Apart from gonadal hormones, prostaglandin is also known to regulate sex differentiation and sexual behavior in teleosts. Prostaglandin $\mathrm{D}_{2}\left(\mathrm{PGD}_{2}\right)$ and $\mathrm{PGE}_{2}$ regulate sex differentiation in zebrafish [20]. Inhibition of $\mathrm{PGE}_{2}$ synthesis by meloxicam, a non-steroidal anti-inflammatory drug (NSAID), resulted in an increased male to female sex ratio in zebrafish [20]. Ibuprofen, another NSAID, has been shown to decrease spawning in medaka [21]. In goldfish, prostaglandin $\left(\mathrm{PGF}_{2 \alpha}\right)$ injections of males and females induced female typical spawning behavior in both males and females when paired with a control partner [15, 22]. $\mathrm{PGF}_{2 \alpha}$ and $15 \mathrm{~K}-\mathrm{PGF}_{2 \alpha}$ released from females act as pheromones to attract males [22]. $\mathrm{PGF}_{2 \alpha}$ and $\mathrm{PGE}_{2}$ can also down-regulate the gonadotropin levels in goldfish [23]. Taken together this suggests that prostaglandins can have a significant effect on teleost gonadal and brain functions.

While hormone [24, 25] and prostaglandin [20] treatment of zebrafish has been shown to result in sex reversal less is known about the role of gonadal hormones in brain organization and activation of sexual behavior. However, transcriptomic studies have shown that the zebrafish brain is sexually dimorphic [26-28]. Compared to the adult mammalian brain the adult zebrafish brain shows a higher potential for neurogenesis [29] suggesting that the zebrafish brain is more plastic and that chemical or hormonal treatment could induce activational and/ or organizational effects, thus altering sexual behavior. To explore the activation of sexual behavior zebrafish were exposed to sex steroids and prostaglandins. Since gonadal hormones and prostaglandins can cause sex reversal in zebrafish, the exposure was performed on adult fish to determine if sexual behavior could be altered during the active reproductive stage.

\section{Methods}

\section{Zebrafish maintenance and exposure}

Wild type zebrafish were obtained from a local pet store in Sweden. The experiments were performed using 6-8 months old zebrafish of F2 and subsequent generations were maintained in a recirculating system (Aquaneering, USA) with a $14 \mathrm{~h}$ light $/ 10 \mathrm{~h}$ dark cycle at $26-27^{\circ} \mathrm{C}$. The fish were fed twice a day with flake food (Tetrarubin, Germany) and Artemia nauplii (Ocean Nutrition, Belgium). The adult zebrafish were exposed individually to $11-\mathrm{KT}, \mathrm{E} 2, \mathrm{PGE}_{2}$ and the $\mathrm{PGD}_{2}$ analog BW 245C (Sigma, USA). All compounds were dissolved 
in water and added to $2 \mathrm{~L}$ exposure glass beakers to $1 \mathrm{~L}$ final volume. Due to the short half-life of prostaglandins, water was completely changed each day. Steroid hormone water was changed every second day. The permits for the animal experiments were obtained from the Ethical Committee in Linköping, Sweden (Permit 32-10).

\section{Brain tissue sampling}

Adult male and female zebrafish were exposed to $25 \mathrm{nM}$ E2 for $24 \mathrm{~h}$. The brains were then removed and dissected into three regions: (1) forebrain containing olfactory bulb and telencephalon; (2) midbrain containing tectum, hypothalamus and pituitary; (3) hindbrain containing cerebellum and medulla. The tissue samples were snap frozen in liquid nitrogen and stored at $-80^{\circ} \mathrm{C}$ until further use.

\section{Sexual behavior}

Zebrafish used for behavioral experiments were maintained in individual $2 \mathrm{~L}$ aquaria. In order to select for sexually active fishes, every 10 days one male and one female zebrafish were placed together and allowed to spawn. For each experiment six couples were used and the experiment was repeated 4 times. After spawning successfully 3-4 times, the male or female zebrafish were individually exposed to E2 (25 nM), KT (25 nM), $\mathrm{PGE}_{2}$ (20, 50 and $100 \mathrm{nM})$ or BW $245 \mathrm{C}(20,50$ and $100 \mathrm{nM})$ for 8 days. On day 9 the treated fish was placed with its control partner. The following morning sexual behavior was observed (male chasing, female being chased and egg release by the females) for $30-40 \mathrm{~min}$. This time was chosen as zebrafish are sexual active immediately after illumination [30]. Male and female mating behavior and spawning was recorded.

In a separate experiment six female zebrafish were individually exposed to E2 (25 nM), 11-KT (25 nM), PGE $(20,50$ and $100 \mathrm{nM})$ or BW $245 \mathrm{C}(20,50$ and $100 \mathrm{nM})$ and paired with a control female. The tail fin of the exposed female was cut to identify it from the control female. For E2 and 11-KT, the experiment was performed four times $(n=6,4$ repetitions) and for prostaglandins the experiment was performed twice $(n=6,2$ repetitions) with different batches of fish. After exposure termination, the fish were kept in normal water and paired again after 2 weeks to observe if the behavioral changes were temporary or permanent. On completion of the behavior studies, the fish were euthanized and sex was determined by gonadal morphology.

\section{RNA extraction and quantitative RT-PCR}

RNA extraction was performed using the NucleoSpin RNA II kit (Macherey-Nagel, Germany) and qRT-PCR analysis was performed as described previously [31].
RNA was quantified using the NanoVue (GE Healthcare, UK) and equal amounts of RNA (500 ng) was used for cDNA synthesis using the qScript cDNA synthesis kit (Quanta Biosciences, USA). Primers were designed for genes that are involved in stress response, sex differentiation, and regulation of brain functions (Additional file 1: Table S1). SYBR Green (Kapa Biosystems, USA) with $150 \mathrm{nM}$ each of forward and reverse primers was used to determine the expression levels of all genes. Thermocycling conditions for SYBR Green consisted of a denaturation step for $5 \mathrm{~min}$ at $95^{\circ} \mathrm{C}$ followed by 40 cycles of $95^{\circ} \mathrm{C}$ for $2 \mathrm{~s}$ and $60^{\circ} \mathrm{C}$ for $30 \mathrm{~s}$. Four biological and two technical replicates were used to study gene expression and the transcript levels were normalized using a housekeeping gene, elongation factor 1a1 (efla1). To avoid use of cross plate reference, each gene was run in one plate. Heat map for analyzed transcript levels were generated using Tableau software, version 8.2 (Tableau software, USA).

\section{Statistical analysis}

The Mann-Whitney U-test and Kruskal-Wallis test followed by Dunn's multiple comparison test was used to analyze behavioral data. For the behavioral studies, the untreated couples (male-female or female-female couples) were used as controls. The differences were considered statistically significant if the p value was $<0.05\left(^{*}\right)$.

Statistical analysis of the qRT-PCR data was performed using the two-tailed non-paired Student's t-test for two group comparison and one way analysis of variance (ANOVA) followed by Dunnett post-test for multiple group comparison. The false discovery rate $(\mathrm{q}<0.05)$ was determined using the FDR online calculator (http:// www.sdmproject.com/software/) and used to adjust the $\mathrm{p}$ values. To further determine if the parametric statistical analyses agreed with non-parametric statistical analyses Kruskal-Wallis test followed by Dunn's multiple comparison as well as Mann-Whitney U-test was used to confirm or reject the results from the parametric analysis. Statistically significant differences that remained after these tests were considered significant if the $\mathrm{P}$ values (parametric tests) were $<0.05\left(\right.$ " $p<0.05$; ${ }^{* *} \mathrm{p}<0.01$; $* * * \mathrm{p}<0.001)$. Statistical analyses were performed using the GraphPad Prism 5 software (GraphPad Software).

Principal component analysis (PCA) is a multivariate data analysis method that incorporates all the data and variables to determine the principal components contributing to the correlation patterns of the data by giving low preference to variables that show non-significant variance and identifying variables and data showing significant variances. The multivariate data analysis and PCA were performed using the SIMCA software, version 13.0.3 (Umetrics, Sweden) at a significance level of 0.05. A score plot showing sample grouping and a loading 
plot indicating the relationship between the variables was used in the analysis. Values that explain the variation, $\mathrm{R}^{2} \mathrm{X}>0.7$ (goodness of fit) and $\mathrm{Q}^{2}>0.4$ (goodness of prediction) were considered to denote an acceptable model when analyzing biological data.

\section{Results and discussion Mating behavior and spawning}

Sex specific behavior including mating behavior, aggression and territorial marking is very common among sexually reproducing animals. During development the male and female brain become differentially organized and both steroid hormones and prostaglandins can activate and alter sexual behavior in mammals as well as in teleosts. In the present study we aimed to determine the influence of exogenously administered sex hormones and prostaglandins on zebrafish mating behavior, spawning and fecundity. Furthermore, analysis of gene expression of male and female zebrafish brains, as well as the effect of E2 exposure was performed to identify sex dependent differences in gene expression.

There were significant changes in mating behavior and spawning success following exposure to E2 and 11-KT (Figure 1). Male fish exposed to $25 \mathrm{nM} \mathrm{E2}$ showed no male mating behavior and no spawning was observed in this group. Earlier studies on zebrafish have shown that exposure to $17 \alpha$-ethynylestradiol (EE2) result in femalebiased sex ratios, and that males that did not undergo sex reversal showed either unaltered male sexual behavior [32] or reduced sexual behavior [33, 34]. In another study EE2 exposed zebrafish males that did not undergo complete sex-reversal but that had reduced testis size or rudimentary ovaries were able to induce spawning behavior when placed with control female [35]. In a separate study it was shown that exposure of zebrafish to low levels of EE2 had no effect on male behavior but rendered the females less interest in EE2 exposed males [36]. Exposure to E2 has been shown to result in decreased male reproductive behavior in other teleosts as well [17-19].

Exposure of female zebrafish to $25 \mathrm{nM} 11-\mathrm{KT}$ resulted in reduced female mating behavior with only $25 \%$ showing normal mating behavior and spawning (Figure 1). Fifty percent of the female fish exposed to $25 \mathrm{nM} 11-\mathrm{KT}$ and paired with a control female showed male mating behavior but did not induce spawning in the control female. 11-KT and MT have been reported to induce male typical behavior in female goldfish [14, 15]. This suggests that androgen exposure in teleost leads to masculinization of the female brain. In this study we did not observe spawning (egg release) from control females when paired with 11-KT exposed females. However, as spawning behavior is very similar to aggressive behavior we cannot differentiate between mating behavior and aggressive behavior using the present setup.

Since, $\mathrm{PGE}_{2}$ and $\mathrm{PGD}_{2}$ are known to influence sex differentiation in zebrafish [20] and as $\mathrm{PGE}_{2}$ is involved in masculinization of female mice [10], we included these two prostaglandins to determine whether they could alter sexual behavior. However, treatment with three different concentrations $(20,50$ and $100 \mathrm{nM})$ of $\mathrm{PGE}_{2}$ and BW245C did not result in any apparent change in sexual behavior or spawning (Figure 1). Injection of $\mathrm{PGE}_{2}$ and $\mathrm{PGF}_{2 \alpha}$ in the third ventricle of goldfish has been shown to down-regulate gonadotropin [23] which suggests that prostaglandins could alter sexual behavior in teleosts. Spawning was induced in $\mathrm{PGF}_{2 \alpha}$ injected female goldfish while injected males showed female typical behavior [15]. $\mathrm{PGF}_{2 \alpha}$ along with $15 \mathrm{~K}-\mathrm{PGF}_{2 \alpha}$ released from female goldfish can act as pheromones inducing male typical behavior and synchronizing sperm release with egg release [22, $37,38]$. Due to the short half-life of $\mathrm{PGF}_{2 \alpha}$, the preferred method of exposure has been through injection, with high efficacies when injected into the ventricles of the brain [38]. The roles of prostaglandins in zebrafish sexual behavior clearly require additional studies.

\section{Brain region differential gene expression}

Zebrafish whole brain transcriptomic analyses have identified sexually dimorphic gene expression patterns [2628]. In order to achieve better resolution we dissected the brain into three regions. This allowed us to determine region-specific expression patterns and to identify sex differences in gene expression. In addition we exposed zebrafish to E2 to determine its role in region specific alteration in gene expression and steroid hormone mediated alterations in sexual behavior. A set of 32 genes was selected for analysis. The selection was based on their involvement in brain functions, sex differentiation and stress responses.

The three brain regions showed distinct differences in genes expression levels with an overall higher expression in the mid- and hindbrain regions compared to the forebrain (Figure 2a). The baxa, elav, gfap, gabbrla, mbpa, $m t f 1$, ptgds, ptges, sirt1 and wt1a genes showed the highest expression in the hindbrain region (Additional file 2: Figure S1-3). Of these genes the gabbr1a, mbpa, mtf1, ptges and sirt 1 genes showed intermediate expression in the midbrain and the lowest expression levels in the forebrain. Three genes (dio2, pmchl and pomca) were highly expressed in the midbrain region (Additional file 2: Figure $\mathrm{S} 1-2$ ). The dio2 gene that was also highly expressed in the hindbrain region is involved in regulation of thyroid hormone levels. The Pro-melanin concentrating hormone-like protein (pmchl) gene and proopiomelanocortin $a($ pomca) gene are involved in melanin regulation. Both 


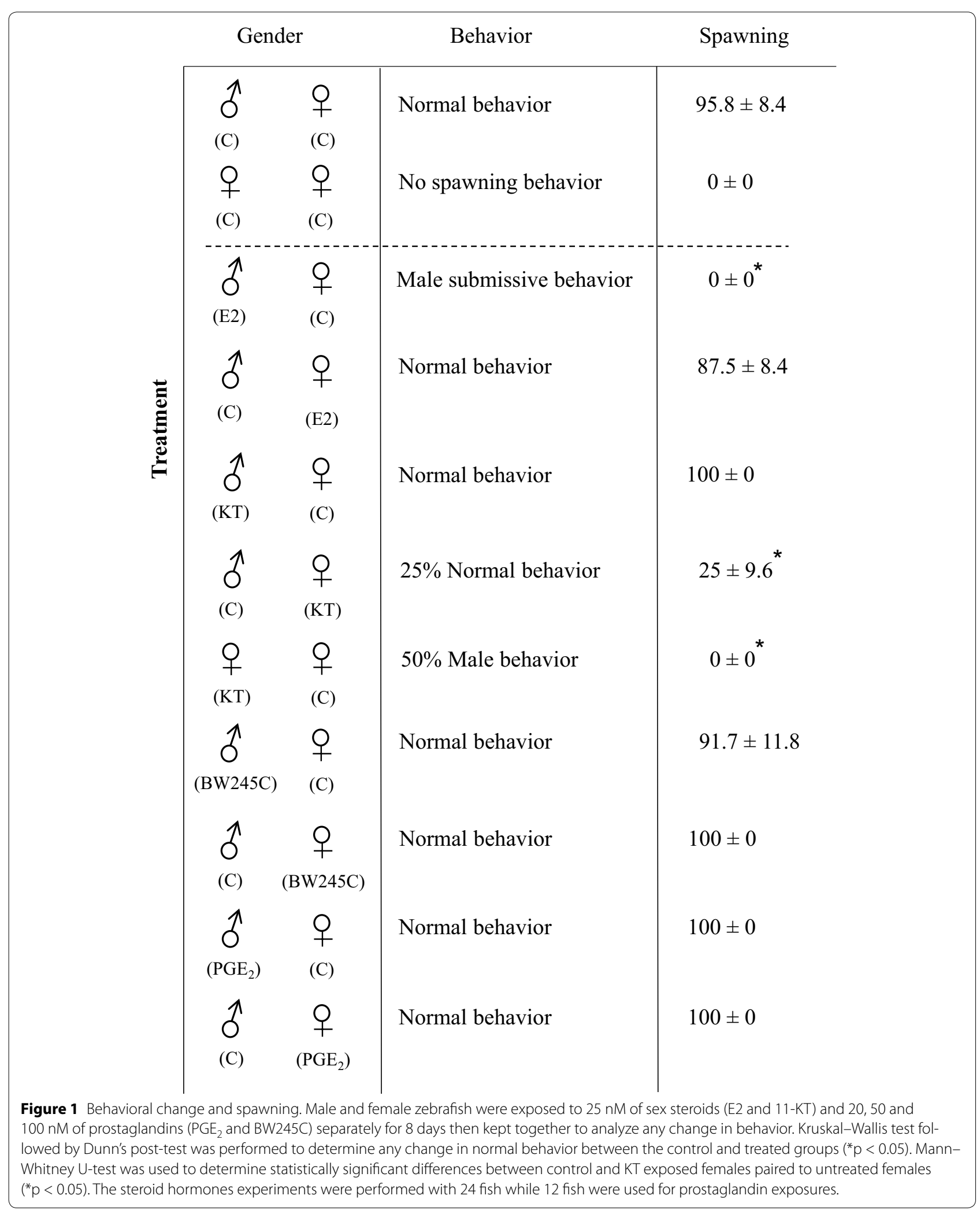




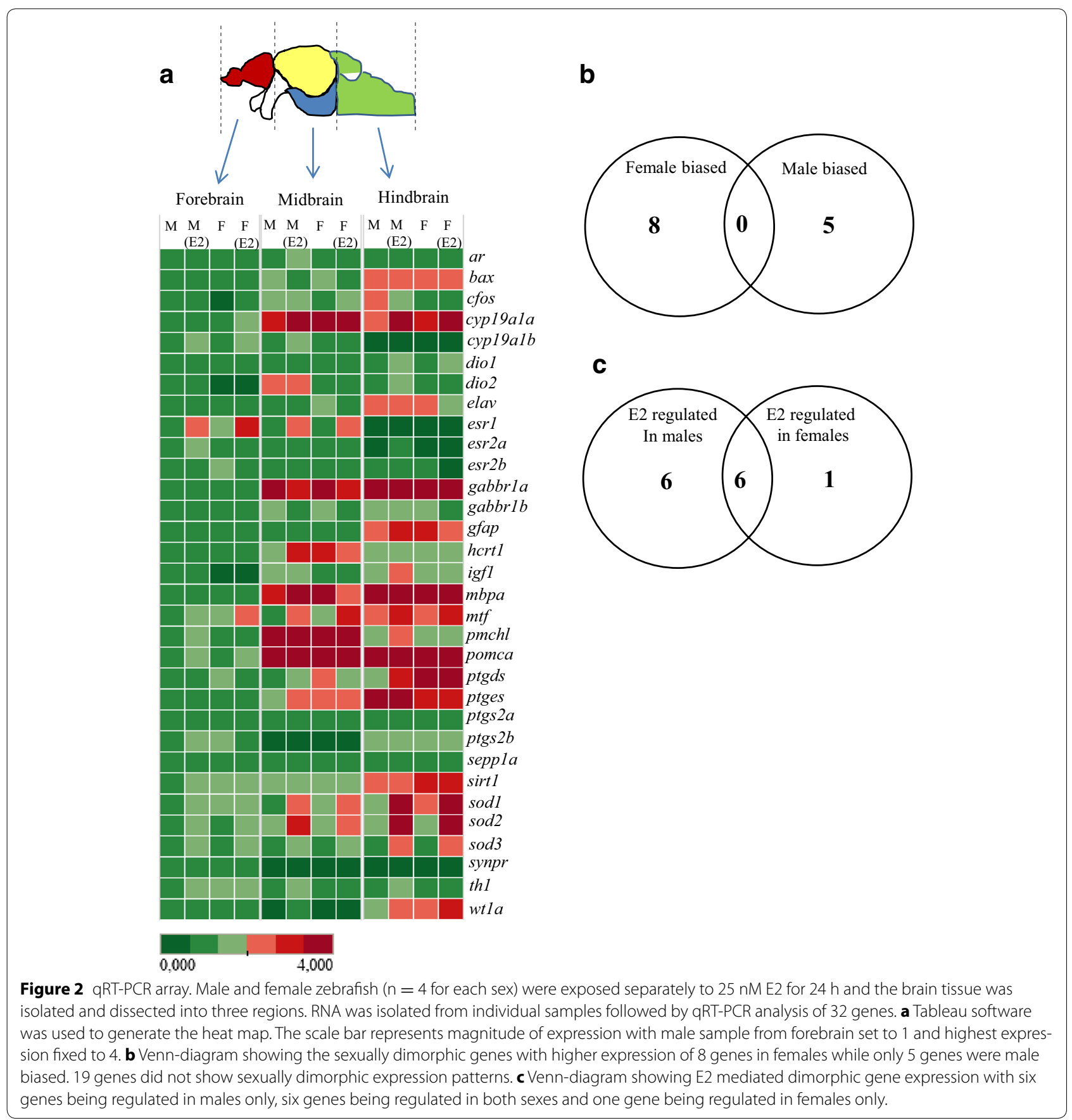

Pomca and Pmchl are also neuroactive peptides, synthesized in the hypothalamus and suggested to control appetite and energy homeostasis [39, 40]. The expression levels of pomca and pmchl were 77 fold and 95 fold higher in the midbrain than in the forebrain, which could be due to high expression of these genes in the pineal gland present in the midbrain. These two genes showed the highest region specific variation of the tested genes. Only one gene, synaptoporin (synpr), showed the highest expression in the forebrain. The cyp19a1b, esr 1 and esr $2 a$ genes showed the lowest expression in the hindbrain (Additional file 2: Figure S1). Cyp19a1b is the brain form of aromatase and it was interesting to note that this gene was not up-regulated by estrogens in the hindbrain region. Overall the hindbrain region showed the largest differences from the other two regions, with ten highly expressed genes and three genes with low expression. As the cerebellum is involved in motor control and as 
it showed the lowest levels of cyp19a1b, esr1 and esr2a estrogen regulated genes it was of interest to determine sex differences in this region and how estrogen treatment would affect this brain region.

\section{Sex biased gene expression}

Out of 32 genes analyzed, 13 genes showed sexually dimorphic expression with 8 genes being female biased and 5 male biased (Figure 2b; Table 1). Female-biased genes expression was observed for two estrogen receptors (esr 1 and esr2b), metal transcription factor 1 (mtf1), prostaglandin synthase $2 b$ (ptgs $2 b$ ), sirtuin 1 (sirt1) and superoxide dismutase $1(\operatorname{sod} 1)$ in the forebrain region (Additional file 2: Figure S1-3). The genes for cytochrome P450, family 19, subfamily A, polypeptide 1b (cyp19a1b), and the $\mathrm{PGD}_{2}$ synthesis enzyme prostaglandin $D$ synthase (ptgds) were high in the hindbrain region (Table 1). Ptgds expression has been observed to be lower in perinatal males mice than in females [41] and has been suggested to be involved in neuroprotection [42]. Ptgds is involved in testis differentiation in mammals [43] and zebrafish [20] but there is no data to link differential expression in the brain with that of sexual behavior.

Male biased gene expression was observed for insulinlike growth factor 1 (igf1) in the forebrain region. $v$-fos FBJ murine osteosarcoma viral oncogene homolog (c-fos) was higher in the midbrain region and gamma-aminobutyric acid $B$ receptor $1 a$ and $1 b$ (gabbrla and gabbr1b) were

Table 1 Genes showing significant dimorphic expression in the three brain regions

\begin{tabular}{lllll}
\hline Genes & $\begin{array}{l}\text { Male/female } \\
\text { biased }\end{array}$ & p-value* & & \\
\cline { 3 - 5 } & & Forebrain & Midbrain & Hindbrain \\
\hline c-fos & Male & $\mathrm{ns}$ & 0.0087 & $\mathrm{~ns}$ \\
cyp19a1b & Female & $\mathrm{ns}$ & $\mathrm{ns}$ & 0.0090 \\
dio2 & Male & 0.0017 & 0.0004 & 0.0256 \\
esr1 & Female & 0.027 & $\mathrm{~ns}$ & $\mathrm{~ns}$ \\
esr2b & Female & 0.0166 & $\mathrm{~ns}$ & $\mathrm{~ns}$ \\
gabbr1a & Male & $\mathrm{ns}$ & $\mathrm{ns}$ & 0.0211 \\
gabbr1b & Male & $\mathrm{ns}$ & $\mathrm{ns}$ & 0.0185 \\
igf1 & Male & $<0.0001$ & $\mathrm{~ns}$ & $\mathrm{~ns}$ \\
mtf & Female & 0.0045 & $\mathrm{~ns}$ & $\mathrm{~ns}$ \\
ptgds & Female & $\mathrm{ns}$ & $\mathrm{ns}$ & 0.0007 \\
ptgs2b & Female & 0.0235 & $\mathrm{~ns}$ & $\mathrm{~ns}$ \\
sirt1 & Female & 0.0007 & $\mathrm{~ns}$ & $\mathrm{~ns}$ \\
sod1 & Female & 0.0121 & $\mathrm{~ns}$ & $\mathrm{~ns}$ \\
\hline nnnyyy & & & &
\end{tabular}

ns not significant.

a Females showed higher expression of eight genes and males showed higher expression of five genes.

* Student's t test was performed to determine statistical significance. higher in the hindbrain region (Table 1). The expression of the deiodinase, iodothyronine, type II (dio2) gene was higher in males than in females in both the fore- and midbrain regions (Table 1 ).

$\mathrm{GnRH}$ neurons are higher in male wrasse and induction of sex change by 11-KT in female teleosts has been implicated to increase the number of $\mathrm{GnRH}$ neurons [13]. Igf1 has been shown to induce GnRH in salmon and zebrafish $[44,45]$ and Igf1 is also involved in the organization of GnRH neurons by influencing migration and differentiation of neural crest cells in juvenile zebrafish [45]. The male-biased igf1 expression in zebrafish forebrain (Additional file 2: Figure S2D) suggests that igf1 could be involved in male behavioral patterning in teleosts. GnRH has been shown to induce c-Fos in mammals, leading to up-regulation of the gonadotropin genes [46]. In the present study $c$-fos expression was higher in the male forebrain and midbrain regions (Additional file 2: Figure S1C) strongly correlating with the igf1 expression in the forebrain. GnRH signaling together with Igfland c-Fos may thus be involved in zebrafish sexual behavior.

In the present study expression of esr 1 was higher in the fore- and midbrain than in the hindbrain (Additional file 2: Figure S1H). ER expression and function can vary depending on the region of expression. ER $\alpha$ has been suggested to control reproductive neuroendocrine functions while ER $\beta$ in regulate non-reproductive functions, including anxiety related behavior [47]. ER $\beta$ has also been linked to the defeminization of the mammalian male brain [48], reduced sexual activity, and sterility in both male and female mice $[49,50]$. Brain aromatase (cyp19a1b), that is involved in E2 synthesis in the brain, showed higher expression in the hindbrain of females (Additional file 2: Figure S1). Exposure to the aromatase inhibitor fadrazole caused protogynous sex change in the blackeye goby by reducing the E2 levels [12]. Fadrazole treatment also induced female to male sex change in zebrafish [51]. In male rats fadrazole leads to reduction in ejaculation and intromission [52], which suggests that E2 is important for masculinization of the mammalian brain while it feminizes the teleost brain.

\section{$17 \beta$-estradiol induced gene expression}

E2 treatment resulted in up-regulation of ten genes and down-regulation of three genes in different brain regions (Figure 2c). The esr1 gene was up-regulated by E2 in all brain regions of both sexes. Three genes, $m t f 1$, sod1 and $\operatorname{sod} 2$ were up-regulated in all brain regions in male fish. The sod genes showed region specific expression in females with sod 1 being up-regulated in the hindbrain, $\operatorname{sod} 2$ being up-regulated in both the mid- and hindbrain and sod3 being up-regulated in the fore- and midbrain. Three genes were down-regulated by E2 and these 
included esr2b (down-regulation in female fore- and midbrain), gabbrla (male hindbrain) and gbbr1b (male midand hindbrain). It is interesting that the hindbrain region, that showed low expression of cyp19a1b, esr 1 and esr $2 a$, also showed minor up-regulation of esr 1 and no regulation of esr $2 a$ or cyp $19 a 1 b$ in female hindbrain following E2 treatment. In order to discriminate between the roles of different ER isoforms it should be possible to use ER specific inhibitors, such as propyl-pyrazole-triol for ER $\alpha$ and diarylpropionitrile for ER $\beta$ separate their roles in modulating teleost sexual behavior. In male zebrafish E2 up-regulated cyp19a1b (fore- and midbrain) and esr $2 a$ (hindbrain), suggesting a sex specific E2 regulatory pattern in this brain region. In a study on mice $A R$ showed higher expression in males than in females and while $\mathrm{T}$ down-regulated $A R$ in both sexes E2 only up-regulated $A R$ in male brains [53]. In the present study we did not observe sexually dimorphic expression of zebrafish ar. It was interesting to note that tyrosine hydroxylase (th1), the rate-limiting step in catecholamine synthesis including dopamine (DA), was up-regulated in male forebrain by E2. DA is involved in modulation of aggressive behavior in zebrafish [54] and in teleost DA is known to inhibit reproduction [55]. The E2 mediated up-regulation of th1 in this study indicates that DA level could be involved in alteration of sexual behavior in treated males.

\section{Multivariate data analysis}

Principal component analysis (PCA) was used to analyze the correlation between gene expression levels and brain regions (Figure 3). The PCA plot comparing the three brain regions with and without $\mathrm{E} 2$ exposure gave a model $\left(\mathrm{R}^{2} \mathrm{X}=0.839\right.$ and $\mathrm{Q}^{2}=0.561$, three component model $)$ showing that the three brain regions had distinct gene expression patterns. PC1 explained $49.5 \%$ of the variation while PC2 and PC3 explained 20.4 and $14.0 \%$ respectively. The PCA score plot showed that male and female control groups as well as treated groups cluster together according to brain region (Figure 3a). The PCA loading plot showed that the expression of majority of the genes was higher in the hindbrain region than the two other regions (Figure $3 \mathrm{~b}$ ). The data shows that the expression of genes involved in androgen and estrogen regulation (ar, esr 1, esr $2 a$, esr $2 b$ and cyp 19a1b) correlated to localization to the forebrain and midbrain regions. Analysis of the effect of E2 treatment on gene expression did not show any significant differences using the PCA analysis. The $\mathrm{R}^{2} \mathrm{X}$ value was below 0.7 when comparing the gene expression between male control and male E2 in the forebrain. All other comparisons gave $\mathrm{R}^{2} \mathrm{X}$ values above 0.7 However, the $\mathrm{Q}^{2}$ values were below 0.4 indicating that the data cannot be used to predict the expression patterns. Likewise, comparisons of gene expression between male and female brain regions gave $R^{2} X$ values $>0.7$ but $\mathrm{Q}^{2}$ values below 0.4. Increasing the number of animals and the number of genes could be of interest in order to better identify overall differences between the brain regions and hormone treatment. The present data suggest that the overall gene expression patterns are highly similar between sexes and following hormone treatment.

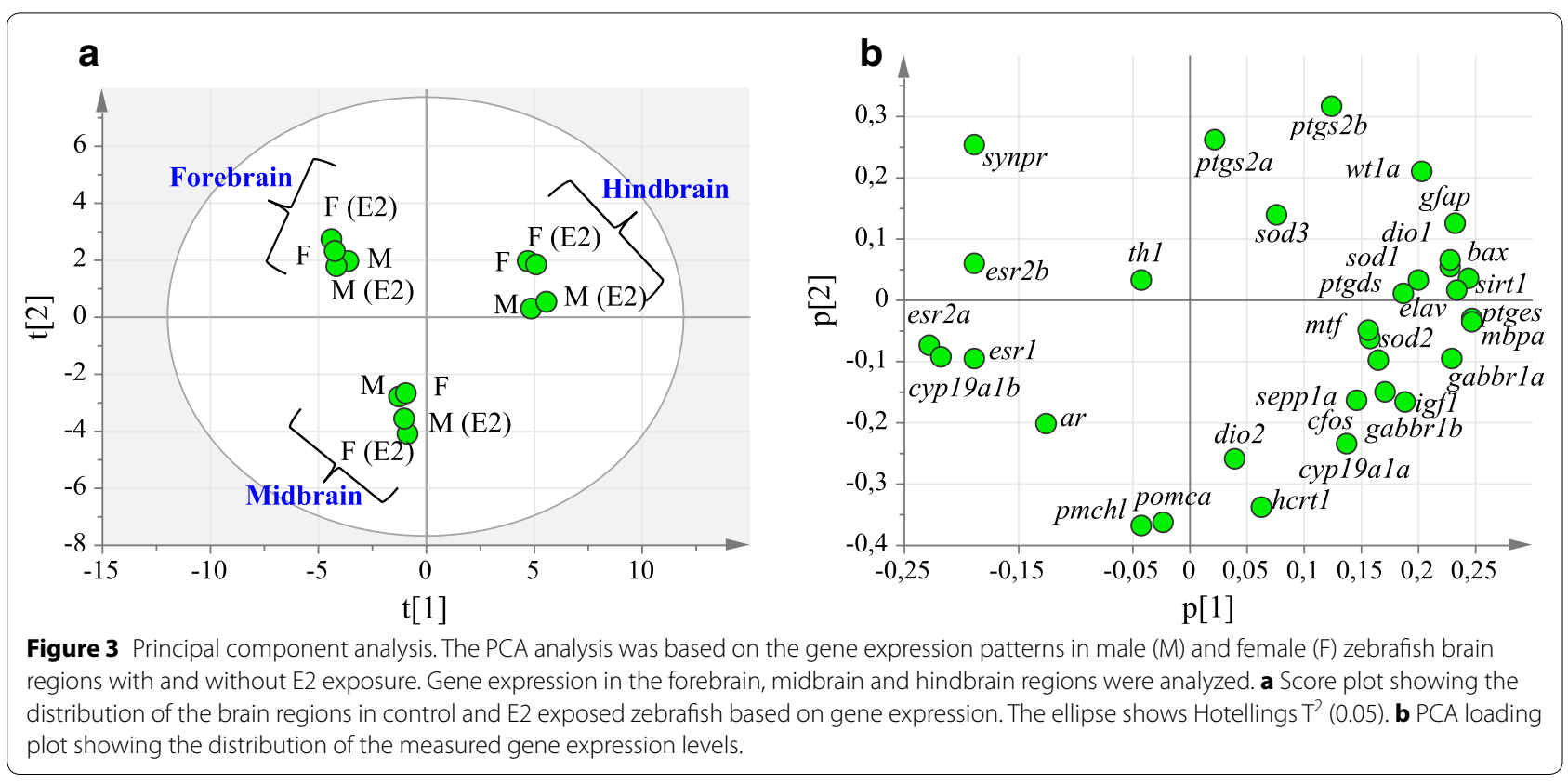


However, the data do indicate that there are large differences between brain regions, independent of sex.

\section{Conclusions}

This study shows that hormonal treatment has an activational role in the zebrafish brain and that the effect of prostaglandins, though not observed in this study cannot be ruled out. E2 treatment appears to feminize the male brain while 11-KT masculinizes the female brain. The ability to induce male and female typical behavior by steroids in opposite sex, suggests that zebrafish have sexually bipotential brains that can be primed either to male or female sexual behavior. Further studies with hormonal exposure and analysis of neuronal activity at both transcriptional and protein level will help to better understand the mechanisms of hormonal action on the teleost brain. This study provides useful information and possible future directions to help unravel the long unsolved mechanisms of gonadal hormones in masculinization as well as feminization of neonatal brain.

\section{Additional files}

\section{Additional file 1: Table S1. Primers used for $\mathrm{QRT} T-P C R$ analysis.}

Additional file 2: Figure S1. Male and female zebrafish were exposed separately to $25 \mathrm{nM} \mathrm{E2}$ for $24 \mathrm{~h}$ and the brain tissue was isolated and dissected into three regions. RNA was isolated from individual samples followed by cDNA synthesis and qRT-PCR analysis. Statistical significance was determined as outlined in the materials and methods section. Statistically significant differences were determined using Student's t test $\left({ }^{*} p<0.05 ;{ }^{* *} p<0.01 ;{ }^{* * *} p<0.001\right) . n=4$. Figure S2. Male and female zebrafish were exposed separately to $25 \mathrm{nM} \mathrm{E2}$ for $24 \mathrm{~h}$ and the brain tissue was isolated followed by CDNA synthesis and qRT-PCR analysis. Statistical significance was determined as outlined in the materials and methods section. Statistically significant differences were determined using Student's t test $\left({ }^{*} p<0.05 ;{ }^{* *} p<0.001\right) . n=4$. Figure S3. Male and female zebrafish were exposed separately to $25 \mathrm{nM}$ E2 for $24 \mathrm{~h}$ and the brain tissue was isolated followed by cDNA synthesis and GRT-PCR analysis. Statistical significance was determined as outlined in the materials and methods section. Statistically significant differences were determined using Student's t test $\left({ }^{*} p<0.05 ;{ }^{* *} p<0.01 ;{ }^{* * *} p<0.001\right) . n=4$.

\section{Authors' contributions}

PEO and AP designed the study. AP performed the experimental studies. PEO and AP performed the statistical analysis. Both authors read and approved the final manuscript.

\section{Acknowledgements}

The research was financed by the Knowledge Foundation, Sweden and Örebro University, Sweden (to PEO).

\section{Compliance with ethical guidelines}

Competing interests

The authors declare that they have no competing interests.

Received: 31 December 2014 Accepted: 25 June 2015

Published online: 13 August 2015

\section{References}

1. Ngun TC, Ghahramani N, Sanchez FJ, Bocklandt S, Vilain E (2011) The genetics of sex differences in brain and behavior. Front Neuroendocrinol 32(2):227-246

2. McCarthy MM, Arnold AP, Ball GF, Blaustein JD, De Vries GJ (2012) Sex differences in the brain: the not so inconvenient truth. J Neurosci 32(7):2241-2247

3. Wu MV, Shah NM (2011) Control of masculinization of the brain and behavior. Curr Opin Neurobiol 21(1):116-123

4. Juntti SA, Coats JK, Shah NM (2008) A genetic approach to dissect sexually dimorphic behaviors. Horm Behav 53(5):627-637

5. Phoenix CH, Goy RW, Gerall AA, Young WC (1959) Organizing action of prenatally administered testosterone propionate on the tissues mediating mating behavior in the female guinea pig. Endocrinology 65:369-382

6. Raskin K, de Gendt K, Duittoz A, Liere P, Verhoeven G, Tronche F et al (2009) Conditional inactivation of androgen receptor gene in the nervous system: effects on male behavioral and neuroendocrine responses. J Neurosci 29(14):4461-4470

7. Juntti SA, Tollkuhn J, Wu MV, Fraser EJ, Soderborg T, Tan S et al (2010) The androgen receptor governs the execution, but not programming, of male sexual and territorial behaviors. Neuron 66(2):260-272

8. Ahmed El, Zehr JL, Schulz KM, Lorenz BH, DonCarlos LL, Sisk CL (2008) Pubertal hormones modulate the addition of new cells to sexually dimorphic brain regions. Nat Neurosci 11(9):995-997

9. MacLusky NJ, Naftolin F (1981) Sexual differentiation of the central nervous system. Science 211(4488):1294-1302

10. Amateau SK, McCarthy MM (2004) Induction of PGE2 by estradiol mediates developmental masculinization of sex behavior. Nat Neurosci 7(6):643-650

11. Godwin J (2010) Neuroendocrinology of sexual plasticity in teleost fishes. Front Neuroendocrinol 31(2):203-216

12. Kroon FJ, Liley NR (2000) The role of steroid hormones in protogynous sex change in the Blackeye goby, Coryphopterus nicholsii (Teleostei: Gobiidae). Gen Comp Endocrinol 118(2):273-283

13. Godwin J (2009) Social determination of sex in reef fishes. Semin Cell Dev Biol 20(3):264-270

14. Stacey N, Kobayashi M (1996) Androgen induction of male sexual behaviors in female goldfish. Horm Behav 30(4):434-445

15. Saoshiro S, Kawaguchi Y, Hayakawa Y, Kobayashi M (2013) Sexual bipotentiality of behavior in male and female goldfish. Gen Comp Endocrinol 181:265-270

16. Wai EH, Hoar WS (1963) The secondary sex characters and reproductive behavior of gonadectomized sticklebacks treated with methyl testosterone. Can J Zool 41(4):611-628

17. Bjerselius R, Lundstedt-Enkel K, Olsen H, Mayer I, Dimberg K (2001) Male goldfish reproductive behaviour and physiology are severely affected by exogenous exposure to 17beta-estradiol. Aquat Toxicol 53(2):139-152

18. Bayley M, Nielsen JR, Baatrup E (1999) Guppy sexual behavior as an effect biomarker of estrogen mimics. Ecotoxicol Environ Safe 43(1):68-73

19. Oshima Y, Kang IJ, Kobayashi M, Nakayama K, Imada N, Honjo T (2003) Suppression of sexual behavior in male Japanese medaka (Oryzias latipes) exposed to 17beta-estradiol. Chemosphere 50(3):429-436

20. Pradhan A, Olsson PE (2014) Juvenile ovary to testis transition in zebrafish involves inhibition of ptges. Biol Reprod 91(2):33

21. Flippin JL, Huggett D, Foran CM (2007) Changes in the timing of reproduction following chronic exposure to ibuprofen in Japanese medaka, Oryzias latipes. Aquat Toxicol 81(1):73-78

22. Kobayashi M, Sorensen PW, Stacey NE (2002) Hormonal and pheromonal control of spawning behavior in the goldfish. Fish Physiol Biochem 26(1):71-84

23. Peter RE, Billard R (1976) Effects of third ventricle injection of prostaglandins on gonadotropin secretion in goldfish, Carassius auratus. Gen Comp Endocrinol 30(4):451-456

24. Schulz RW, Bogerd J, Male R, Ball J, Fenske M, Olsen LC et al (2007) Estrogen-induced alterations in amh and dmrt1 expression signal for disruption in male sexual development in the zebrafish. Environ Sci Technol 41(17):6305-6310

25. Orban L, Sreenivasan R, Olsson PE (2009) Long and winding roads: testis differentiation in zebrafish. Mol Cell Endocrinol 312(1-2):35-41 
26. Sreenivasan R, Cai M, Bartfai R, Wang X, Christoffels A, Orban L (2008) Transcriptomic analyses reveal novel genes with sexually dimorphic expression in the zebrafish gonad and brain. PLoS One 3(3):e1791

27. Arslan-Ergul A, Adams MM (2014) Gene expression changes in aging zebrafish (Danio rerio) brains are sexually dimorphic. BMC Neurosci 15:29

28. Wong RY, McLeod MM, Godwin J (2014) Limited sex-biased neural gene expression patterns across strains in Zebrafish (Danio rerio). BMC Genom 15:905

29. Kizil C, Kaslin J, Kroehne V, Brand M (2012) Adult neurogenesis and brain regeneration in zebrafish. Dev Neurobiol 72(3):429-461

30. Spence R, Gerlach G, Lawrence C, Smith C (2008) The behaviour and ecology of the zebrafish, Danio rerio. Biol Rev Camb Philos Soc 83(1):13-34

31. Pradhan A, Khalaf H, Ochsner SA, Sreenivasan R, Koskinen J, Karlsson M et al (2012) Activation of NF-kappaB protein prevents the transition from juvenile ovary to testis and promotes ovarian development in zebrafish. J Biol Chem 287(45):37926-37938

32. Nash JP, Kime DE, Van der Ven LT, Wester PW, Brion F, Maack G et al (2004) Long-term exposure to environmental concentrations of the pharmaceutical ethynylestradiol causes reproductive failure in fish. Environ Health Perspect 112(17):1725-1733

33. Larsen MG, Hansen KB, Henriksen PG, Baatrup E (2008) Male zebrafish (Danio rerio) courtship behaviour resists the feminising effects of 17alpha-ethinyloestradiol-morphological sexual characteristics do not. Aquat Toxicol 87(4):234-244

34. Colman JR, Baldwin D, Johnson LL, Scholz NL (2009) Effects of the synthetic estrogen, 17alpha-ethinylestradiol, on aggression and courtship behavior in male zebrafish (Danio rerio). Aquat Toxicol 91(4):346-354

35. Larsen MG, Bilberg K, Baatrup E (2009) Reversibility of estrogenic sex changes in zebrafish (Danio rerio). Environ Toxicol Chem/SETAC 28(8):1783-1785

36. Baatrup E, Henriksen PG (2015) Disrupted reproductive behavior in unexposed female zebrafish (Danio rerio) paired with males exposed to low concentrations of 17alpha-ethinylestradiol (EE2). Aquat Toxicol 160:197-204

37. Munakata A, Kobayashi M (2010) Endocrine control of sexual behavior in teleost fish. Gen Comp Endocrinol 165(3):456-468

38. Sorensen PW, Hara TJ, Stacey NE, Goetz FW (1988) F-Prostaglandins function as potent olfactory stimulants that comprise the postovulatory female sex-pheromone in goldfish. Biol Reprod 39(5):1039-1050

39. Pritchard LE, Turnbull AV, White A (2002) Pro-opiomelanocortin processing in the hypothalamus: impact on melanocortin signalling and obesity. J Endocrinol 172(3):411-421

40. Maulon-Feraille L, Della Zuana O, Suply T, Rovere-Jovene C, Audinot $\checkmark$, Levens $\mathrm{N}$ et al (2002) Appetite-boosting property of pro-melaninconcentrating hormone(131-165) (neuropeptide-glutamic acid-isoleucine) is associated with proteolytic resistance. J Pharmacol Exp Ther 302(2):766-773
41. Sakakibara M, Uenoyama Y, Minabe S, Watanabe Y, Deura C, Nakamura S et al (2013) Microarray analysis of perinatal-estrogen-induced changes in gene expression related to brain sexual differentiation in mice. PLoS One 8(11):e79437

42. Liang X, Wu L, Hand T, Andreasson K (2005) Prostaglandin D2 mediates neuronal protection via the DP1 receptor. J Neurochem 92(3):477-486

43. Moniot B, Declosmenil F, Barrionuevo F, Scherer G, Aritake K, Malki S et al (2009) The PGD2 pathway, independently of FGF9, amplifies SOX9 activity in Sertoli cells during male sexual differentiation. Development 136(11):1813-1821

44. Luckenbach JA, Dickey JT, Swanson P (2010) Regulation of pituitary GnRH receptor and gonadotropin subunits by IGF1 and GnRH in prepubertal male coho salmon. Gen Comp Endocrinol 167(3):387-396

45. Onuma TA, Ding Y, Abraham E, Zohar Y, Ando H, Duan C (2011) Regulation of temporal and spatial organization of newborn GnRH neurons by IGF signaling in zebrafish. J Neurosci 31(33):11814-11824

46. Ely HA, Mellon PL, Coss D (2011) GnRH induces the c-Fos gene via phosphorylation of SRF by the calcium/calmodulin kinase II pathway. Mol Endocrinol 25(4):669-680

47. Lund TD, Rovis T, Chung WC, Handa RJ (2005) Novel actions of estrogen receptor-beta on anxiety-related behaviors. Endocrinology 146(2):797-807

48. Kudwa AE, Bodo C, Gustafsson JA, Rissman EF (2005) A previously uncharacterized role for estrogen receptor beta: defeminization of male brain and behavior. Proc Natl Acad Sci USA 102(12):4608-4612

49. Antal MC, Petit-Demouliere B, Meziane H, Chambon P, Krust A (2012) Estrogen dependent activation function of ERbeta is essential for the sexual behavior of mouse females. Proc Natl Acad Sci USA 109(48):19822-19827

50. Antal MC, Krust A, Chambon P, Mark M (2008) Sterility and absence of histopathological defects in nonreproductive organs of a mouse ERbetanull mutant. Proc Natl Acad Sci USA 105(7):2433-2438

51. Takatsu K, Miyaoku K, Roy SR, Murono Y, Sago T, Itagaki H et al (2013) Induction of female-to-male sex change in adult zebrafish by aromatase inhibitor treatment. Sci Rep 3:3400

52. Bonsall RW, Clancy AN, Michael RP (1992) Effects of the nonsteroidal aromatase inhibitor, Fadrozole, on sexual behavior in male rats. Horm Behav 26(2):240-254

53. Kumar RC, Thakur MK (2004) Androgen receptor mRNA is inversely regulated by testosterone and estradiol in adult mouse brain. Neurobiol Aging 25(7):925-933

54. Dahlbom SJ, Backstrom T, Lundstedt-Enkel K, Winberg S (2012) Aggression and monoamines: effects of sex and social rank in zebrafish (Danio rerio). Behav Brain Res 228(2):333-338

55. Dufour S, Sebert ME, Weltzien FA, Rousseau K, Pasqualini C (2010) Neuroendocrine control by dopamine of teleost reproduction. J Fish Biol 76(1):129-160

\section{Submit your next manuscript to BioMed Central and take full advantage of:}

- Convenient online submission

- Thorough peer review

- No space constraints or color figure charges

- Immediate publication on acceptance

- Inclusion in PubMed, CAS, Scopus and Google Scholar

- Research which is freely available for redistribution

Submit your manuscript at 